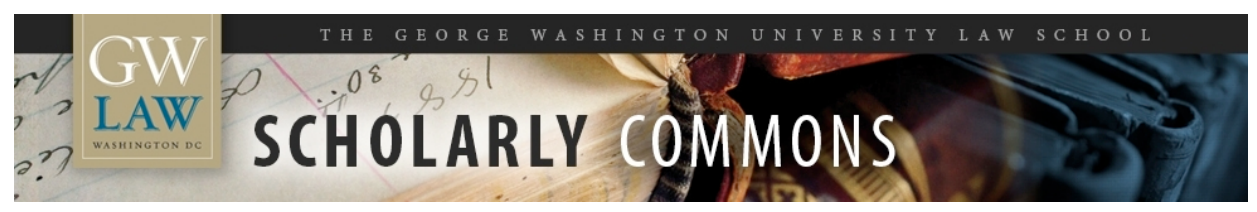

\title{
Coercive vs. Cooperative Enforcement: Effect of Enforcement Approach On Environmental Management
}

\author{
Robert L. Glicksman \\ George Washington University Law School, rglicksman@law.gwu.edu \\ Dietrich Earnhart
}

Follow this and additional works at: https://scholarship.law.gwu.edu/faculty_publications

Part of the Law Commons

\section{Recommended Citation}

42 Int'I Rev. of L. \& Econ. 135 (2015)

This Article is brought to you for free and open access by the Faculty Scholarship at Scholarly Commons. It has been accepted for inclusion in GW Law Faculty Publications \& Other Works by an authorized administrator of Scholarly Commons. For more information, please contact spagel@law.gwu.edu. 


\title{
Coercive vs. cooperative enforcement: Effect of enforcement approach on environmental management
}

\author{
Dietrich H. Earnhart ${ }^{\mathrm{a}, *}$, Robert L. Glicksman ${ }^{\mathrm{b}}$ \\ a Department of Economics, University of Kansas, United States \\ b School of Law, George Washington University, United States
}

\section{A R T I C L E I I N F O}

\section{Article history:}

Received 27 March 2014

Received in revised form 13 January 2015

Accepted 5 February 2015

Available online 19 February 2015

\section{Keywords:}

Environmental management

Compliance

Enforcement approach

Self-audits

\begin{abstract}
A B S T R A C T
A spirited debate explores the comparative merits of two different approaches to the enforcement of regulatory law: the coercive approach, which emphasizes the deterrence of noncompliance through inflexibly imposed sanctions, and the cooperative approach, which emphasizes the inducement of compliance through flexibility and assistance. Both scholarly and policymaking communities are interested in this topic of enforcement approach within the realms of finance, tax compliance, occupational safety, food and drug safety, consumer product safety, and environmental protection. To inform this debate, our study explores enforcement of environmental protection laws where the debate has been especially spirited yet lacking in much empirical evidence. Specifically our study empirically analyzes the effects of these two approaches on environmental management practices linked to compliance with wastewater discharge limits imposed on chemical manufacturing facilities. For this analysis, we view the enforcement approach as representing a relationship between a regulator and a regulated entity that is measured in multiple dimensions so that we are able to explore the extent of cooperation or coercion. The empirical results reveal that a more cooperative relationship induces better environmental management.
\end{abstract}

(C) 2015 Elsevier Inc. All rights reserved.

\section{Introduction}

For years a spirited debate has explored the comparative merits of two different approaches to the enforcement of regulatory law: the coercive approach, which emphasizes the deterrence of non-compliance through sanctions, and the cooperative approach, which emphasizes the inducement of compliance through flexible means such as compliance assistance designed to induce facilities to address noncompliance pro-actively. Both scholarly and policymaking communities are interested in these enforcement approaches as applied to finance, tax compliance, occupational safety, food and drug safety, consumer product safety, and environmental protection (Ayers and Braithwaite, 1992). Debate over environmental enforcement is especially significant in that compliance assurance a contentious issue in the post-2000 EPA policy agenda (EPA, 2000; Glicksman and Earnhart, 2007).

Under the coercive model, the deterrence of violations is the fundamental purpose of environmental enforcement (Markel, 2000, 2005; Mintz, 1995). The imposition of enforcement sanctions is the

\footnotetext{
* Corresponding author at: Department of Economics, University of Kansas, 435 Snow Hall, Lawrence, KS 66045, United States.

E-mail address: Earnhart@ku.edu (D.H. Earnhart).
}

most effective way to induce compliance with regulatory obligations. Under the cooperative model, enforcement focuses more on compliance than deterrence based on the premise that regulated facilities face incentives to comply other than enforcement threats (Stoughton et al., 2001; Andreen, 2007). In this light, a coercive approach may even be counterproductive by engendering intransigence and ill will from facilities.

Over the years, environmental enforcement in the United States has shifted from traditional, deterrence-based enforcement toward a more partnership-based, less adversarial approach that uses multiple tools to induce compliance (Stoughton et al., 2001). During the 1990s, EPA adopted enforcement policies designed to provide a more flexible approach to inducing regulatory compliance by offering "compliance incentives" and "compliance assistance" to regulated facilities (Andreen, 2007). Similarly, many states have replaced aspects of traditional enforcement with some form of cooperation (Andreen, 2007). However, no shift from a coercive to a cooperative approach has been complete. Despite the dichotomy between these approaches, agencies rarely rely exclusively on one approach; studies of agency enforcement reveal that "most enforcers use a flexible, hybrid strategy that includes elements of both coercion and cooperation" (Rechtschaffen, 2004).

Despite the debate over enforcement approaches, relatively little empirical research has compared the two approaches. 
Specifically, few studies empirically test these competing theories about how best to induce environmental compliance or spur regulated facilities to undertake better environmental management that in turn should lead to environmental compliance.

This study addresses the paucity of empirical evidence by examining the effects of the two enforcement approaches on environmental management practices of chemical manufacturing facilities regulated under the Clean Water Act (CWA). We conducted a survey of all chemical manufacturing facilities regulated between 1999 and 2001. The responses indicate that, although most regulated facilities describe their relationships with wastewater regulators as generally either cooperative or coercive, these facilities also regard some particular aspects of their relationships as more consistent with one enforcement approach, while others are more consistent with the other approach. Thus, the relationship between regulator and facility involves multiple dimensions.

Empirical results indicate that a more cooperative enforcement approach induces better environmental management. In other words, as the relationship between the regulator and regulated entity becomes more cooperative, the regulated entities improve their environmental management.

\section{Literature review}

This section reviews the relevant theoretical and empirical literature on the coercive and cooperative enforcement approaches in the environmental realm.

\subsection{Theoretical studies}

The theoretical literature identifies two models of environmental enforcement: coercive and cooperative. The coercive model is premised on the idea that regulated facilities' principal motivations revolve around the maximization of expected benefits net of costs (Malloy, 2003; Spence, 2001). Facilities comply only when the costs of non-compliance, e.g., fines, outweigh the benefits of noncompliance, e.g., avoided treatment costs (Vandenbergh, 2003). ${ }^{1}$

The coercive model proceeds on the premise that increasing the certainty and severity of penalties deters non-compliance (Becker, 1968; Kagan et al., 2003). Thus, the essential task for enforcement agencies is to make penalties high enough and the probability of detection/enforcement great enough that it becomes economically irrational for facilities to violate the law (Cohen, 2000).

In contrast, the cooperative model proceeds on the assumption that businesses are influenced by a mix of civic and societal motives. This model postulates that businesses are generally inclined to comply with laws (Rechtschaffen and Markell, 2003). The cooperative model's emphasis on compliance over the deterrence of non-compliance alters the use of both inspections and enforcement actions. Within the cooperative model, an inspection is designed to facilitate compliance by providing advice to regulated facilities (Rechtschaffen and Markell, 2003), rather than to detect violations and collect evidence for subsequent enforcement actions, as within the coercive model. Similarly, the cooperative model's emphasis on compliance alters the use of enforcement. Regulated facilities may be afforded more opportunities to avoid sanctions by resolving non-compliance before enforcement is pursued than under the coercive model, i.e., the cooperative approach "emphasizes flexible or selective enforcement that takes into consideration the particular circumstances of an observed violation" (Scholz, 1984).

\footnotetext{
1 Costs of non-compliance include damage to the business's reputation, potential tort liability, and legal system expenses (Karpoff et al., 2005; Vandenbergh, 2003; Rechtschaffen and Markell, 2003).
}

As an important extension, if businesses are generally committed to compliance, sanctions may prove counter-productive by making regulated facilities resentful and less likely to cooperate with regulators in the future (Burby and Paterson, 1993; Kagan et al., 2003). In many contexts, random variations in facility operations or unexpected events may occasionally cause noncompliance. A coercive response to these events may breed strong resentment or ill will.

In essence, the cooperative model relies on flexible guidelines rather than uniform rules, an emphasis on ex ante prevention of violations rather than ex post sanctions for noncompliance, and compliance assistance from regulators (Burby, 1995). This model rests on the premise that regulated facilities should respond more positively to regulators' suggestions on how to achieve compliance than to the threat of coercive sanctions (Rechtschaffen and Markell, 2003).

\subsection{Empirical studies}

Relatively few empirical studies analyze the use of cooperative enforcement strategies. Harrison (1995) states that past studies hailing the merits of cooperative enforcement lack empirical support. Even less research directly compares coercive and cooperative strategies. $^{2}$

Some studies analyze the efficacy of overall enforcement strategies. Harrison (1995) analyzes the regulation of water pollution in Canada. She finds that rates of compliance with water pollution controls are significantly lower in the pulp and paper industry in Canada, where the cooperative approach to enforcement predominates, than in the United States. Burby (1995) examines states' programs to reduce erosion and sedimentation pollution in urban areas. He concludes that "[t]he best performing state programs [for nonpoint sources of water pollution] tend to be those that use a highly coercive approach". Burby and Paterson (1993) examine whether the cooperative approach is better suited to inducing compliance with performance standards than with specification(or design) standards. They conclude that "a cooperative approach ... has much more impact on the degree of compliance attained for performance standards than for specification standards." Andreen (2007) examines compliance rates for major dischargers under the CWA, finding that compliance rates remained static during the period in which many states replaced traditional enforcement with some type of cooperative enforcement.

While these empirical studies help to inform our understanding of enforcement strategies and their relative efficacy, only one study gathers facility-specific data on the type of relationship between regulators and regulated facilities and no study considers this relationship as consisting of multiple dimensions. In contrast, the present study examines both of these aspects. ${ }^{3}$

\section{Empirical application}

To examine the relative effects of coercive and cooperative enforcement strategies, this study examines a specific element relating to compliance with environmental protection regulations: the frequency of wastewater-related self-audits implemented by U.S. chemical manufacturing facilities whose wastewater discharges were regulated by effluent limits imposed within the

\footnotetext{
2 According to Rechtschaffen (1998), “[t]he argument that cooperation works better than deterrence to achieve compliance with environmental law ... is largely untested". Most of the evidence is anecdotal.

3 Notable studies explore specific cooperative approaches within a standard coercive enforcement arrangement (Short and Toffel, 2010; Helland, 1998; Stretesky and Gabriel, 2005; Toffel and Short, 2011).
} 
CWA's National Pollutant Discharge Elimination System (NPDES) between 1999 and 2001. By focusing on regulated facilities, our analysis is able to focus on environmental audits that include an assessment of compliance with the noted NPDES effluent limits.

We choose the industrial sector of chemical and allied products as the focus of our study because it is an excellent vehicle for examining the efficacy of enforcement strategies on regulated facilities' environmental management. First, EPA has demonstrated a strong interest in this sector as evidenced by its study (joint with the Chemical Manufacturing Association [CMA], which later became the American Chemistry Council [ACC]) on the root causes of this sector's non-compliance (EPA, 1999) and its study on this sector's compliance history [Chemical Industry National Environmental Baseline Report 1990-1994 (EPA 305-R-96-002)]. During the study period, EPA regarded two chemical industrial sub-sectors, industrial organics and chemical preparations, as priority industrial sectors. Second, this sector is expected to display a wide scope in the extent of facilities' environmental management. Consistent with this expectation, a substantial portion of the sampled facilities never audit over the three-year sample period, while several audit their operations at least monthly. Third, this sector is responsible for a significant portion of the nation's industrial output and a significant portion of all wastewater discharges by facilities subject to CWA regulation. ${ }^{4}$

Facilities may control their wastewater discharges in various ways. In general, facilities use end-of-pipe treatment technologies or proactive environmental management practices, such as self-audits, which collectively may constitute an environmental management system (EMS). Examination of the latter is relevant to policy development and trends in business management. Both the EPA and state environmental agencies have encouraged the adoption of environmental management systems by offering technical assistance, recognition, and regulatory benefits to facilities that employ an environmental management system (Crow, 2000). Similarly "business-led" initiatives have promoted participation in trade association programs emphasizing environmental management codes, such as the Responsible Care program of the American Chemistry Council, or the adoption of international certification standards for environmental management, such as the International Standards Organization (ISO) 14001 program.

Some empirical studies focus on the presence or absence of an EMS (e.g., Barla, 2007; Arimura et al., 2008). However, some of the EMS components may not represent activities that effectively lead to improved environmental performance (Barla, 2007). Rather than examining the mere presence of a broad set of management activities or analyzing a count of practices, this study focuses on the use of a particularly tangible management activity - environmental regulatory compliance audit - that is strongly expected to improve performance. Previous empirical studies support this expectation (Khanna and Widyawati, 2011; Short and Toffel, 2010; Toffel and Short, 2011); in particular, Earnhart and Harrington (2014) reveal that more audits lead to better compliance with wastewater discharge limits. As important, since the mid-1980s, the EPA has promoted self-audits as a tool for improving environmental performance, especially environmental compliance (Evans et al., 2011). As evidence of this promotion, the EPA has integrated environmental auditing into its compliance and enforcement strategy; specifically, it began in 1997 to include increased environmental auditing in its strategic plan for improving compliance with environmental regulations (Evans et al., 2011; EPA, 1997).

\footnotetext{
${ }^{4}$ The chemical industry is not necessarily representative of all sectors. Indeed, its attributes contribute to our study's interest, e.g., some chemical firms are prompted to control their pollution through participation in the Responsible Care program, an initiative supported by the American Chemistry Council.
}

A compliance audit represents a systematic, documented, and objective review of a facility's operations, which allows the facility to evaluate its compliance relative to audit criteria (American Society for Testing and Materials (ASTM), 2003). The EPA defines an environmental audit as "a systematic, documented, periodic and objective review by regulated facilities of facility operations and practices related to meeting environmental requirements". ${ }^{5}$ Rather than examining the presence of an audit program, this study focuses on the frequency of audits for three reasons. First, most guidelines recommend that environmental self-audits be conducted at least annually (Ebihara and Irminger, 2005). Thus, many facilities may conduct at least one audit per year. Second, regularly scheduled self-audits contribute to both stronger overall environmental management and more consistent compliance with relevant regulations (Wilson and Thomas, 1998). Thus, greater frequency should lead to better environmental management. Third, we wish to examine the extent of environmental management adoption by measuring the frequency with which facilities audit.

The chosen sample and focus on environmental management facilitates an effective analysis of chemical manufacturing facilities' responses to regulatory efforts to control wastewater-related pollution. These efforts begin with the issuance of facility-specific permits, which impose effluent limits. To ensure compliance with these limits, the EPA and state agencies periodically inspect facilities and take enforcement actions as needed. Inspections generally represent the backbone of environmental agencies' efforts to monitor compliance and collect evidence for enforcement. As for enforcement, agencies use a mixture of informal enforcement actions (e.g., warning letters) and formal enforcement actions (e.g., administrative orders, fines).

\section{Empirical framework and data collection}

\subsection{Framework}

To assess the relative efficacy of the two enforcement approaches, we estimate the relationship between environmental management, as reflected in self-audits conducted by regulated facilities, and the overall enforcement approach employed against the sampled facilities, while controlling for other influential factors.

We construct a multi-dimensional measure of enforcement approaches. For each dimension, we create a binary indicator that identifies "cooperation" as opposed to "coercion". The first dimension captures the general relationship between the regulator and the regulated facility: (1) generally cooperative or (2) generally coercive. The second dimension captures the prevalence of fair treatment of the facility by the regulator: (1) always fair, (2) sometimes fair, or (3) always unfair. Environmental regulation is commonly perceived by regulated entities as "unfair"; by extension, inflexible enforcement of this regulation might also be perceived as "unfair" (Zinn, 2002). More directly, an excessively stringent deterrence-based approach may be counterproductive by engendering perceptions that enforcement is "unreasonable" (Faure, 2012; Hawkins, 1984). In contrast, a flexible cooperative enforcement approach should mitigate the perceived unfairness and unreasonableness of regulation and enforcement directly. We argue that "always fair" treatment reflects a more cooperative approach, while less than "always fair" treatment reflects a more coercive approach. The third dimension captures the stability of the relationship as reflected in the assignment of regulatory agency officials: the facility typically works (1) with the same individual water regulatory official or (2) with multiple regulatory officials

\footnotetext{
5 “Interim Guidelines on Environmental Auditing Policy Statement," 50 FR 46504 (November 8, 1985), Section II.A.
} 
that vary with circumstances. Typically, working with the same official is more likely to facilitate a cooperative relationship, while working with multiple officials is less likely to do so, i.e., more likely to lead to a coercive relationship. The fourth dimension captures the quality of the working relationship as reflected in a facility's decision to seek assistance from the regulator's supervisor to help resolve a difference of opinion between the facility and its regulator. The absence of a request for assistance reveals a more cooperative relationship, while the presence of a request reveals a more coercive relationship. Similarly, the fifth dimension relates to whether the facility seeks assistance from an elected official. Again, the absence of a request reveals a more cooperative relationship, while the presence of a request reveals a more coercive relationship. The sixth dimension captures the physical proximity of the regulator as reflected in the type of regulatory agency engaging the facility: (1) regional EPA agency or (2) state agency. Closer proximity facilitates a more cooperative relationship, while greater distance may lead to a more coercive relationship. The last dimension captures the level of trust supported by the relationship as reflected in a facility's willingness to allow regulators access to plant operations if regulators arrive unannounced. Greater trust reflects a more cooperative relationship, while less trust reflects a more coercive relationship.

To measure the multi-dimensional enforcement approach, we construct an index by summing across the indicators of cooperation presence for each enforcement strategy dimension. This index distinguishes strategies along a spectrum of coercion-cooperation. The lowest point on the index reflects a strongly coercive strategy, while the highest point reflects a strongly cooperative strategy.

Our empirical analysis then tests these hypotheses: under the coercive model, greater coercion (lower index values) leads to better environmental management. Under the cooperative model, greater cooperation (higher index values) leads to better environmental management.

The analysis controls for the influence of government interventions - inspections and enforcement actions - in two dimensions. The first dimension considers the ex ante general "threat" of receiving an intervention in the future based on the experiences of a large number of facilities, while the second dimension considers adjustments to this general threat based on the specific government interventions taken against particular facilities in the recent past (Cohen, 2000). To calculate the general threats, we count the inspections or enforcement actions taken against all other chemical facilities in the same state (for state inspections) or EPA region (for federal inspections and enforcement) and year, while distinguishing between major and minor facilities. Then we divide each aggregate count by the number of other major or minor chemical facilities operating in the specific state or EPA region and given year. Facilities may make adjustments to these general threats based on their own experiences with recent interventions (Magat and Viscusi, 1990). Consequently, we lag our measures by considering interventions from the preceding calendar year because audits are recorded annually. Without this separation, some audits may actually precede some interventions. The effects of specific government interventions targeted against particular facilities more closely align with the effect of the regulator-regulated entity relationship so our study focuses more attention on specific adjustment and less attention on the general threat.

The expected effects of government interventions on audit frequency depend on the theoretical model. Under the coercive model, both state and federal inspections should induce better environmental behavior. However, under the cooperative model, state inspections should induce better behavior, while federal inspections may induce worse behavior if the presence of federal inspectors is perceived as "heavy handed". While under the coercive model, enforcement should induce better behavior, under the cooperative model, enforcement may induce worse behavior if enforcement is perceived as "heavy handed". The hypotheses derived from the cooperative model relate more strongly to specific adjustment than to the general threat. ${ }^{6}$

Environmental management also depends on facility- and firm-level characteristics: industrial sub-sector (organic chemical indicator and inorganic chemical indicator, with "other chemicals" as benchmark), facility size as reflected in number of employees, facility size based on NPDES classification ("major facility" indicator, with "minor facility" as benchmark), facility age, facility's years of experience in the NPDES regulatory system, and firm ownership structure ("publicly held" indicator, with "privately held" as benchmark).

\subsection{Data sources}

We gather information from various sources. Most important, we implemented a survey of regulated chemical facilities to gather data on the nature of facilities' relationships with wastewater regulators, environmental management practices, especially wastewater self-audits, and facility characteristics (e.g., age). We also gathered publicly available data, including information on firm ownership structure from the EPA Toxic Release Inventory (TRI), Business and Company Resource Center, and Compustat/Research Insight databases. We collected data from the EPA Permit Compliance System (PCS) database on each facility's (1) location, (2) major/minor classification, and (3) four-digit standard industrial classification code. From the EPA PCS and Docket databases, we gathered data on inspections and enforcement actions.

To implement our survey, we first identified the population of regulated facilities based on a full extract drawn from the EPA PCS database as of September, 2001. We identified 1003 currently regulated facilities. ${ }^{7}$ Of those facilities contacted between April of 2002 and March of 2003, 267 facilities completed at least $90 \%$ of the survey, implying a $27 \%$ response rate. This rate is comparable to previous large-scale surveys of industrial sectors (e.g., Arimura et al., 2008, 2011; Nakamura et al., 2001) and lies above the average response rate of $21 \%$ as identified by a review of 183 studies based on business surveys published in academic journals (Paxson, 1992). [The online appendix addresses the possible concern of sample selection bias.]

\subsection{Summary of data}

This subsection summarizes the dependent and primary independent variables. Table 1a tabulates the distribution of self-audits performed per year by a particular facility, which reveals that nearly $86 \%$ of the sample facilities conduct at least one audit per year. As expected, the distinction between no audits and some audits does not divide the sample strongly. The median facility performs

\footnotetext{
${ }^{6}$ Other regulatory factors may affect the extent of environmental management. The analysis attempts to control for other variation in regulatory pressure by including EPA regional indicators as regressors. The use of these regional indicators is a blunt tool for controlling for "un-measured" variation in monitoring and enforcement across space. Inclusion of these indicators forces the analysis to identify the effect of the overall enforcement approach based exclusively on intra-regional variation, which may be insufficient for the task. Consequently, we reserve the inclusion of regional indicators as only a means for assessing the robustness of the empirical results.

7 We applied the following criteria to facilities: (1) possessed an NPDES permit (2) faced restrictions on their wastewater discharges, (3) were operating as of 2002 and (4) discharged pollutants into surface water bodies. We focus on facilities discharging into surface waterways because facilities discharging into publicly owned treatment systems, i.e., industrial users, face a distinctively different regulatory regime.
} 
Table 1

Statistical summary.

\begin{tabular}{|c|c|c|c|c|}
\hline Audit count & $N$ & Pct & Cumulative $N$ & Cumulative Pct \\
\hline \multicolumn{5}{|c|}{ (a) Distribution of audit counts ${ }^{\mathrm{a}}$} \\
\hline 0 & 85 & 13.89 & 85 & 13.89 \\
\hline 1 & 241 & 39.38 & 326 & 53.27 \\
\hline 2 & 70 & 11.44 & 396 & 64.71 \\
\hline 3 & 18 & 2.94 & 414 & 67.65 \\
\hline 4 & 67 & 10.95 & 481 & 78.59 \\
\hline 5 & 12 & 1.96 & 493 & 80.56 \\
\hline 6 & 6 & 0.98 & 499 & 81.54 \\
\hline 8 & 3 & 0.49 & 502 & 82.03 \\
\hline 10 & 1 & 0.16 & 503 & 82.19 \\
\hline 12 & 64 & 10.46 & 567 & 92.65 \\
\hline 13 & 1 & 0.16 & 568 & 92.81 \\
\hline 17 & 2 & 0.33 & 570 & 93.14 \\
\hline 20 & 2 & 0.33 & 572 & 93.46 \\
\hline 24 & 7 & 1.14 & 579 & 94.61 \\
\hline 27 & 1 & 0.16 & 580 & 94.77 \\
\hline 36 & 3 & 0.49 & 583 & 95.26 \\
\hline 40 & 4 & 0.65 & 587 & 95.92 \\
\hline 45 & 4 & 0.65 & 591 & 96.57 \\
\hline 50 & 4 & 0.65 & 595 & 97.22 \\
\hline 52 & 17 & 2.78 & 612 & 100.00 \\
\hline Variable & & & & \\
\hline
\end{tabular}

(b) Means and standard deviations of regression variables

Dependent variable

Audit count

5.580

10.959

Primary explanatory variable

Regulator-regulated entity relationship index (count: 0-7)

5.990

1.046

Individual dimensions of regulator-regulated entity relationship

Generally cooperative (vs. generally coercive)

Always fair treatment (vs. sometimes fair treatment)

0.967

0.392

Same individual regulator (vs. multiple regulators)

$0.582 \quad 0.494$

No request for assistance from regulator's supervisor (vs. request)

No request for assistance from elected official (vs. request)

State is typical regulator (vs. federal)

Always Likely to allow unannounced access (vs. likely/somewhat likely)

0.791

0.407

$0.946 \quad 0.226$

$0.994-0.040$

Control factors

Organic chemical manufacturing (vs. "other chemicals")

Inorganic chemical manufacturing (vs. "other chemicals")

Major facility classification (vs. Minor Facility)

Facility employees (count)

Age of facility (years)

Facility's experience with NPDES system (years)

Facility owned by publicly-held firm (vs. privately-held firm)

Preceding Calendar year state inspections (count)

Preceding calendar year federal inspections (count)

Preceding calendar year enforcement actions (count)

Annual state inspections of others/\# of other facilities (count/facility)

Annual federal inspections of others/\# of other facilities (count/facility)

Annual enforcement actions at others/\# of other facilities (count/facility)

EPA region $1(1,0)^{c}$

EPA region $2(1,0)^{c}$

EPA region $3(1,0)^{c}$

EPA region $4(1,0)$

EPA region $5(1,0)^{c}$

EPA region $6(1,0)^{c}$

EPA region $7(1,0)^{c}$

$\begin{array}{rr}0.895 & 0.306 \\ 0.443 & 0.497 \\ 0.301 & 0.459 \\ 0.420 & 0.494 \\ 268.558 & 491.257 \\ 43.433 & 24.022 \\ 18.727 & 8.387 \\ 0.641 & 0.480 \\ 0.784 & 1.499 \\ 0.042 & 0.246 \\ 0.178 & 1.344 \\ 0.808 & 1.056 \\ 0.035 & 0.056 \\ 0.115 & 0.312 \\ 0.034 & 0.182 \\ 0.085 & 0.279 \\ 0.142 & 0.349 \\ 0.263 & 0.441 \\ 0.160 & 0.367 \\ 0.204 & 0.403 \\ 0.070 & 0.256\end{array}$

Dimension of relationship

(1)

(2)

(3)

(4)

(5)

(6)

(c) Correlations between individual dimensions of regulator-regulated entity relationship ${ }^{\mathrm{d}}$

(1) Likelihood of allowing regulator access to

plant without announcement: always likely

vs. not

(2) Typical type of regulator: state vs. federal

(3) Stability of interaction: same individual vs. multiple individuals

(4) Treatment of regulated entity by regulator: always fair treatment vs. not always fair

(5) Overall relationship: cooperative vs. coercive

(6) Requested assistance from regulator's supervisor: no vs. yes

$\begin{array}{ll}0.089 & \\ (0.162) & \\ 0.021 & 0.106 \\ (0.745) & (0.096) \\ -0.055 & 0.070 \\ (0.382) & (0.267) \\ -0.054 & -0.015 \\ (0.388) & (0.811) \\ 0.015 & -0.054 \\ (0.808) & (0.394)\end{array}$

0.224
$(0.000)$
0.099
$(0.115)$
0.059
$(0.350)$

0.345

(0.000)

0.222

(0.000)

0.2222

(0.000) 
Table 1 (Continued)

\begin{tabular}{|c|c|c|c|c|c|c|c|}
\hline \multicolumn{2}{|c|}{ Dimension of relationship } & $(1)$ & $(2)$ & (3) & (4) & $(5)$ & $(6)$ \\
\hline \multicolumn{2}{|c|}{$\begin{array}{l}\text { (7) Requested assistance from elected official: } \\
\text { no vs. yes }\end{array}$} & $\begin{array}{l}0.055 \\
(0.383)\end{array}$ & $\begin{array}{l}-0.024 \\
(0.709)\end{array}$ & $\begin{array}{l}0.033 \\
(0.602)\end{array}$ & $\begin{array}{l}0.080 \\
(0.205)\end{array}$ & $\begin{array}{l}0.076 \\
(0.227)\end{array}$ & $\begin{array}{l}0.221 \\
(0.000)\end{array}$ \\
\hline Index & $N$ & & & Cumula & & Cumula & \\
\hline \multicolumn{8}{|c|}{ (d) Distribution of regulator-regulated entity relationship index ${ }^{\mathrm{e}}$} \\
\hline 2 & 1 & \multicolumn{2}{|c|}{0.47} & 1 & \multicolumn{3}{|c|}{0.47} \\
\hline 3 & 4 & \multicolumn{2}{|c|}{1.86} & 5 & \multicolumn{3}{|c|}{2.33} \\
\hline 4 & 16 & \multicolumn{2}{|c|}{7.44} & 21 & \multicolumn{3}{|c|}{9.77} \\
\hline 5 & 38 & \multicolumn{2}{|c|}{17.67} & 59 & \multicolumn{3}{|c|}{27.44} \\
\hline 6 & 73 & \multicolumn{2}{|c|}{33.95} & 132 & \multicolumn{3}{|c|}{61.40} \\
\hline 7 & 83 & \multicolumn{2}{|c|}{38.60} & 215 & \multicolumn{3}{|c|}{100.00} \\
\hline
\end{tabular}

a Based on sample used for estimation of year-specific equations.

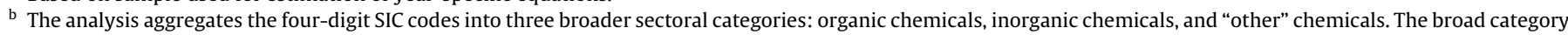

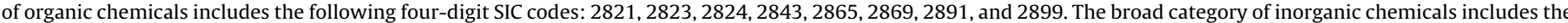
following four-digit SIC codes: 2812, 2813, 2816, 2819, 2873, and 2874.

c Omitted category= EPA Regions 8 and 9.

d Based on full survey sample; $p$-values shown in parentheses.

e Based on sample used for between-group estimation.

a single audit per year. A majority of facilities (54\%) conduct one to three audits per year. ${ }^{8}$

Table 1b summarizes the dimensions reflecting a facility's relationship with its regulator. Only $3 \%$ of facilities regard their relationship as "generally coercive," while $97 \%$ regard it as "generally cooperative." Moreover, $19 \%$ of facilities report that regulatory treatment is "sometimes fair, sometimes unfair", while $81 \%$ report that it is "always fair". No facility reports that its treatment is "always unfair". Table 1c also indicates that 58\% of facilities typically work with the same regulator, while $42 \%$ typically work with multiple regulators. Additionally, $79 \%$ of facilities did not seek help from the supervisor of the regulator, while $21 \%$ did. Similarly, $95 \%$ of facilities did not request assistance from an elected official, while $5 \%$ did. In addition, $99 \%$ of facilities report that they typically work with state regulators, while only $1 \%$ report that they typically work with federal regulators. ${ }^{9}$ Lastly, $90 \%$ of facilities are "always likely" to allow regulators access to plant operations if regulators arrive unannounced, while $9 \%$ are either "likely" or "somewhat likely" to allow access, yet no facility is "not at all likely" to allow access.

Next, the analysis compares the responses to the individual relationship-related questions by calculating Pearson pairwise correlation coefficients between all possible pairs of relationship elements; Table 1c reports these correlations. In general, these statistics reveal only weak correlation between the various measures capturing the relationship between the regulator and the regulated entity. Of the 21 pairwise correlations, only six are positive and statistically significantly different from zero (i.e., $p \leq 0.10$ ). Of these significantly positive correlations, the largest magnitude is only 0.35 , indicating limited connection between these pairs of responses. As important, five of the correlations are actually negative though the coefficients are insignificantly different from zero. The remaining 10 correlations are positive but insignificantly different from zero. This analysis demonstrates that the relationship between a regulator and a regulated entity consists of multiple dimensions. In other words, no single underlying dimension seems to reflect all of the responses.

Based on this conclusion, the analysis calculates an index of coercion-cooperation by summing across the seven dichotomous

\footnotetext{
8 Wastewater compliance is typically assessed monthly via submission of a monthly discharge monitoring report (DMR) to a regulatory authority; $10 \%$ of facilities conduct self-audits monthly.

9 State regulators predominate because EPA has delegated NPDES permitting authority to state environmental agencies in most states. As of 2006, only five states had not received authority to administer at least some aspect of the NPDES permit program.
}

indicators of cooperation-coercion. ${ }^{10}$ Table $1 \mathrm{~d}$ tabulates the distribution of this index. Nearly $39 \%$ of the facilities experience a fully cooperative relationship with their regulators, while no facility experiences a fully coercive relationship. Only $2 \%$ of facilities experience a relationship that is more coercive than cooperative (index $\leq 3$ ), with $7 \%$ facing a relationship that is a reasonably balanced mix of the two (index $=4$ ). Thus, the strongest variation in the index lies at the upper reaches of cooperation ( $5 \leq$ index $\leq 7)$.

As with many studies of environmental management relying on surveys, of the 267 facilities who completed most of the survey, only 215 provide complete information for our full analysis.

Table $1 \mathrm{~b}$ provides a statistical summary of all the formulated variables.

\section{Estimation methods and results}

\subsection{Estimation methods}

This subsection describes estimation methods used to examine the link from enforcement approach to environmental management while addressing important econometric considerations.

As one important econometric consideration, our primary explanatory variable - enforcement approach - may be an endogenous regressor. The validity of this concern over endogeneity varies across the components included in the enforcement approach index. On one end of the spectrum, certain components clearly represent decisions made by the regulator or facility, e.g., facilities' requests for assistance from an elected official. On the other end, certain components are most likely exogenously determined, e.g. primary type of regulator - state vs. federal - depends on whether a state has primacy over the NPDES program within its borders.

We assess this endogeneity concern by implementing tests of exogeneity. For this implementation, we use three instruments expected to affect the enforcement approach but not independently affect facilities' audit decisions: (1) time since the state agency gained primacy to implement the NPDES program, (2) two-year lagged state inspections, and (3) two-year lagged federal inspections. ${ }^{11}$ Based on both partial F-test and Minimum Eigenvalue statistics, these instruments appear relevant. Based on both

\footnotetext{
10 If a facility is "always likely" to allow a regulator access to the facility's operations, the relationship is deemed "cooperative", otherwise, the relationship is deemed "coercive".

11 Anton et al. (2004) use additionally lagged measures of inspections in order to test the exogeneity of environmental management when environmental performance is the dependent variable.
} 
Sargan and Basman Test of Overidentifying Restrictions statistics, the instruments do not appear invalid. Most important, both WuHausman and Durban Test of Exogeneity statistics fail to reject the null hypothesis of exogeneity. (All of these conclusions are fully robust to the time period analyzed and the regressor set used for estimation. ${ }^{12}$ These conclusions are also fully robust to the use of a single instrument - time since gaining primacy, which represents the strongest instrument from a theoretical perspective. Specifically, after controlling for government interventions and the overall enforcement approach, state primacy should not directly affect facilities' audit decisions.) Consequently, we do not employ an instrumental variables estimator since the benefits seem outweighed by the costs of reduced efficiency in the estimates when the regressors appear uncorrelated with the error process.

In addition, the dependent variable of audit frequency represents a sum of discrete events, i.e., count data. Accordingly, we employ two pairs of count data estimators: Poisson and negative binomial, each in standard form and zero inflated form (Cameron and Trivedi, 1998).

The collected data measure environmental management over multiple years (1999-2001) for each facility. To accommodate the panel data structure, we employ two estimation approaches. The first approach uses a between-group estimator, which collapses the panel data into a single cross-section by calculating the sample means for the dependent variable and all the independent variables and then estimates the functional relationship based on the calculated mean values. The second approach considers each year of data as a separate cross-section and estimates the functional relationship for each year separately within a joint system of equations that constructs a separate equation for each year. Joint estimation of the three year-specific equations increases the efficiency of the estimates by exploiting the correlation across the three equations' error terms. ${ }^{13}$

The analysis considers three regressor sets. Model 1 excludes the government intervention-related factors. Model 2 includes only the specific adjustment factors. Model 3 includes both the specific adjustment and the general threat factors. By excluding the government-related factors, Model 1 allows the estimated effects of the overall enforcement strategy to absorb all of the influences associated with any differential use of inspections and enforcement actions. Moreover, the analysis considers two model sets: Model Set $A$ includes the regressors for between-group estimation, while Model Set B includes the regressors for year-specific estimation. Tables $2 \mathrm{a}$ and $2 \mathrm{~b}$ reports the between-group estimates for Model Set A (Models A1-A3). Tables 3a and 3b reports the year-specific estimates for Model Set B (Models B1-B3). Tables 2a and 3a display the standard Poisson estimates; Tables $2 \mathrm{~b}$ and $3 \mathrm{~b}$ display the standard negative binomial estimates.

The overdispersion tests shown in Tables $2 \mathrm{~b}$ and $3 \mathrm{~b}$ reveal that the negative binomial estimates appear to dominate the Poisson estimates. Still, we interpret both estimate sets as part of our

\footnotetext{
12 Depending on the time period and regressor set, the partial $F$-test $p$-values lie between 0.0001 and 0.0069 , the overidentifying restrictions test $p$-values lie between 0.260 and 0.849 , and the exogeneity test $p$-values lie between 0.154 and 0.492 .

13 While the dependent variable - audit frequency - and most of the regressors vary over the sample period (1999-2001), the measures capturing the overall enforcement strategy do not vary over the sample period for a given facility. The survey questions generating these measures either explicitly or implicitly instruct the respondents to consider the preceding three-year period as a whole. Due to this lack of variation over time, use of the between-group estimator seems the most appropriate estimation approach since this approach considers the three-year period as a single cross section. Then again, the analysis may reasonably assume that the measures of overall enforcement strategy sufficiently apply to each individual year as well as they apply to the whole three-year period.
}

robustness assessment. Yet when these two estimate sets differ, more weight should be given to the negative binomial estimates.

Finally, we assess the zero inflated estimates. Vuong tests assess whether the zero inflated form of a data count estimator dominates the standard form. Test statistics reveal that the zero inflated form dominates in the case of the Poisson estimator $(p \leq 0.006)$ but not in the case of the negative binomial estimator $(p \geq 0.501)$. Given this mixed message and extra complexity of the zero inflated form, we assess the zero inflated estimates, without tabulation, only as part of our robustness assessment, while focusing on the estimates for the primary regressor.

\subsection{Interpretation of effects not related to enforcement and monitoring}

This subsection interprets the effects not related to enforcement and monitoring starting with the between-group estimates. The following conclusions are robust across the three models and between the Poisson and negative binomial estimates except as noted. First, inorganic chemical manufacturing facilities audit less frequently than "other" chemical manufacturing facilities. (Poisson estimates of Model 3 also reveal that organic chemical manufacturing facilities audit less frequently than "other chemical" manufacturing facilities.) Second, major facilities audit more frequently than minor facilities (based on the Poisson estimates but not the negative binomial estimates). Third, the shift from minor class to major class prompts more audits, yet facilities with more employees audit less frequently than facilities with fewer employees (in both cases, based on Poisson but not negative binomial estimates). These results reveal economies or diseconomies of scale with respect to environmental management depending on the proxy of facility size. Fourth, older facilities audit more frequently (but not based on negative binomial estimates of Models A2 and A3). Fifth, more experienced facilities audit less frequently. Sixth, facilities owned by publicly held firms audit less frequently than facilities owned by privately held firms.

This assessment reveals that the Poisson estimation generates more traction for the control factors yet both the Poisson and negative binomial estimates support conclusions that are generally robust to the inclusion of the government intervention factors as regressors.

As shown in Table 3, the year-specific estimates support identical conclusions in the case of the Poisson estimates and highly similar conclusions in the case of the negative binomial estimates (even then coefficient signs are identical except in four minor cases where $p \geq 0.8) .^{14}$

Although not tabulated, the Poisson zero inflated estimates support nearly identical conclusions and the negative binomial zero inflated estimates support highly similar conclusions.

\subsection{Interpretation of effects related to enforcement and monitoring}

This subsection interprets the effects of the overall enforcement strategy on environmental management, along with the effects of intervention-related factors. Both the Poisson and negative binomial results strongly reveal that greater cooperation apparently leads to more frequent audits. As shown in Table 3, this conclusion

\footnotetext{
14 Negative binomial between-group estimates prove statistically significant yet the following year-specific estimates prove insignificant for the following factors: years of experience with the NPDES system in 1999 (Model B1) and in 2001 (Model B3), facility age in 2001 (Model B1), and firm ownership structure in 2001 (Models B2 and B3). The opposite holds the following factors: facility age in 2000 (Model B3) and number of facility employees in 2001 (Model B3).
} 
Table 2

Between-group estimation of audit counts: Model Set A.

\begin{tabular}{|c|c|c|c|c|c|c|}
\hline \multirow[t]{2}{*}{ Variable $^{a}$} & \multicolumn{2}{|l|}{ Model A1 } & \multicolumn{2}{|l|}{ Model A2 } & \multicolumn{2}{|l|}{ Model A3 } \\
\hline & Coeff & $p$-Value & Coeff & $p$-Value & Coeff & $p$-Value \\
\hline \multicolumn{7}{|l|}{ (a) Poisson between-group estimation } \\
\hline Regulator-regulated entity relationship index & 0.2239 & 0.000 & 0.2264 & 0.000 & 0.2148 & 0.000 \\
\hline Organic chemical manufacturing (vs. “other”) & -0.0682 & 0.314 & -0.0876 & 0.199 & -0.1500 & 0.031 \\
\hline Inorganic chemical manufacturing (vs. "other") & -0.7403 & 0.000 & -0.6623 & 0.000 & -0.7239 & 0.000 \\
\hline Major facility classification (vs. minor) & 0.4960 & 0.000 & 0.5536 & 0.000 & 0.7556 & 0.000 \\
\hline Facility employees (count) & -0.0002 & 0.018 & -0.0003 & 0.002 & -0.0004 & 0.000 \\
\hline Age of facility (years) & 0.0052 & 0.000 & 0.0044 & 0.000 & 0.0042 & 0.000 \\
\hline Facility's experience with NPDES system (years) & -0.0264 & 0.000 & -0.0299 & 0.000 & -0.0266 & 0.000 \\
\hline Facility owned by publicly-held firm (vs. privately-held) & -0.4798 & 0.000 & -0.3407 & 0.000 & -0.3509 & 0.000 \\
\hline Preceding calendar year state inspections (count) & & & 0.0200 & 0.423 & -0.0317 & 0.308 \\
\hline Preceding calendar year federal inspections (count) & & & -3.5875 & 0.000 & -3.3506 & 0.000 \\
\hline Preceding calendar year enforcement actions (count) & & & 0.1451 & 0.000 & 0.1388 & 0.000 \\
\hline Annual state inspections of others/\# of other facilities & & & & & 0.0784 & 0.061 \\
\hline Annual federal inspections of others/\# of other facilities & & & & & -4.5394 & 0.000 \\
\hline Annual enforcement actions at others/\# of other facilities & & & & & 0.2132 & 0.196 \\
\hline LR test of zero slopes $\left(\chi^{2}\right)$ & 302.6 & 0.000 & 391.9 & 0.000 & 419.5 & 0.000 \\
\hline Pseudo $R^{2}$ & 0.1 & & & & & \\
\hline Goodness of fit $\left(\chi^{2}\right)$ & 2169 & 0.000 & 2079 & 0.000 & 2052 & 0.000 \\
\hline Sample size & & & & & & \\
\hline (b) Negative binomial between-group estimation & & & & & & \\
\hline Regulator-regulated entity relationship index & 0.2189 & 0.016 & 0.2177 & 0.018 & 0.2183 & 0.019 \\
\hline Organic chemical manufacturing (vs. "other") & -0.0291 & 0.904 & -0.0732 & 0.762 & -0.2198 & 0.408 \\
\hline Inorganic chemical manufacturing (vs. "other") & -0.7972 & 0.003 & -0.6978 & 0.011 & -0.8052 & 0.005 \\
\hline Major facility classification (vs. Minor) & 0.2732 & 0.163 & 0.2266 & 0.303 & 0.4596 & 0.125 \\
\hline Facility employees (count) & -0.0002 & 0.375 & -0.0003 & 0.246 & -0.0003 & 0.140 \\
\hline Age of facility (years) & 0.0067 & 0.099 & 0.0056 & 0.166 & 0.0047 & 0.255 \\
\hline Facility's experience with NPDES system (years) & -0.0255 & 0.045 & -0.0273 & 0.030 & -0.0239 & 0.067 \\
\hline Facility owned by publicly-held firm (vs. privately-held) & -0.5127 & 0.021 & -0.4210 & 0.062 & -0.3954 & 0.082 \\
\hline Preceding calendar year state inspections (count) & & & 0.1034 & 0.160 & 0.0729 & 0.498 \\
\hline Preceding calendar year federal inspections (count) & & & -2.5560 & 0.003 & -2.6360 & 0.002 \\
\hline Preceding calendar year enforcement actions (count) & & & 0.1321 & 0.278 & 0.1420 & 0.339 \\
\hline Annual state inspections of others/\# of other facilities & & & & & 0.0344 & 0.813 \\
\hline Annual federal inspections of others/\# of other facilities & & & & & -4.0640 & 0.144 \\
\hline Annual enforcement actions at others/\# of other facilities & & & & & 0.1601 & 0.779 \\
\hline LR test of zero slopes $\left(\chi^{2}\right)$ & 30.54 & 0.000 & 40.22 & 0.000 & 42.52 & 0.000 \\
\hline Pseudo $R^{2}$ & 0.0 & & & & & \\
\hline Overdispersion test $\left(\chi^{2}\right)$ & 1581 & 0.000 & 1501 & 0.000 & 1476 & 0.000 \\
\hline Sample size & & & & & & \\
\hline
\end{tabular}

a Each model also includes an intercept term.

is fully robust to the time period analyzed. Thus, greater cooperation leads to more audits in each year of the sample period. As important, this conclusion is fully robust to the choice of regressor set. Thus, greater cooperation leads to better environmental management even when the analysis controls for the differential use of inspections and enforcement actions and the threat of their use. (The single exception is the negative binomial estimate of Model B2 in 1999 where the $p$-value slips to 0.14). Lastly, this conclusion is fully robust to the use of zero inflated Poisson and negative binomial estimators. ${ }^{15}$

To complement this interpretation, we next interpret the effects of intervention-related factors. We first assess the between-group estimation results, as shown in Table 2. The conclusions are robust between the Poisson and negative binomial estimates unless noted. The estimation results reveal that a greater use of federal inspections apparently prompts less frequent audits, as does the greater threat of federal inspections (based on Poisson estimates), yet a greater threat of state inspections appears to prompt more frequent

\footnotetext{
15 We also assess robustness by exploring whether the results are sensitive to the inclusion of EPA regional indicators as regressors. Despite the inclusion of these regressors, the effect of the cooperation-coercion index remains significant based on both the between-group and year-specific estimation results for both the Poisson estimator and negative binomial estimator.
}

audits (based on Poisson estimates). These results are consistent with the reported conclusion that greater cooperation prompts more frequent audits. Perhaps federal inspections are more coercive, undermining efforts to audit frequently. In contrast, state inspectors are more cooperative, improving audit frequency. This latter conclusion is somewhat weak as it is drawn from the threat of state inspections rather than the differential use of such inspections. In contrast to the differential use of federal inspections, a greater use of enforcement actions prompts more frequent audits (based on Poisson estimates) perhaps because properly targeted enforcement improves environmental management even though enforcement may be perceived as coercive. These conclusions are fully robust to the choice of regressor set. These points notwithstanding, the dominant negative binomial estimates identify only a single significant effect: more federal inspections lead to less frequent audits.

Moreover, conclusions depend on the time period analyzed as shown in Table 3. Comparison of the between group and yearspecific Poisson estimates reveal these differences. First, greater use of state inspections prompts more audits in 1999 but fewer audits in 2001. Second, greater use of enforcement actions induces fewer audits in 1999 but more audits in 2001. Third, a greater threat of state inspections induces more audits in 2001 but not in 1999 or 2000. Fourth, a greater threat of enforcement induces more audits in 1999 and 2000 but fewer audits in 2001. Comparison of 
Table 3

Joint estimation of year-specific equations for audit counts: Model Set B.

\begin{tabular}{|c|c|c|c|c|c|c|}
\hline \multirow[t]{2}{*}{ Variable $^{\mathrm{a}}$} & \multicolumn{2}{|l|}{ Model B1 } & \multicolumn{2}{|l|}{ Model B2 } & \multicolumn{2}{|l|}{ Model B3 } \\
\hline & Coeff & $p$-Value & Coeff & $p$-Value & Coeff & $p$-Value \\
\hline \multicolumn{7}{|l|}{ (a) Joint Poisson estimation } \\
\hline \multicolumn{7}{|l|}{ Year $1999[N=215]$} \\
\hline Regulator-regulated entity relationship index & 0.1472 & 0.000 & 0.1503 & 0.000 & 0.1631 & 0.000 \\
\hline Organic chemical manufacturing (vs. "other") & -0.0184 & 0.805 & -0.0103 & 0.889 & -0.0432 & 0.575 \\
\hline Inorganic chemical manufacturing (vs. "other") & -0.8817 & 0.000 & -0.8507 & 0.000 & -0.8581 & 0.000 \\
\hline Major facility classification (vs. minor) & 0.3863 & 0.000 & 0.3802 & 0.000 & 0.4470 & 0.000 \\
\hline Facility employees (count) & -0.0003 & 0.004 & -0.0003 & 0.004 & -0.0004 & 0.002 \\
\hline Age of facility (years) & 0.0064 & 0.000 & 0.0057 & 0.000 & 0.0057 & 0.000 \\
\hline Facility's experience with NPDES system (years) & -0.0175 & 0.000 & -0.0206 & 0.000 & -0.0207 & 0.000 \\
\hline Facility owned by publicly-held firm (vs. privately-held) & -0.4347 & 0.000 & -0.4244 & 0.000 & -0.4209 & 0.000 \\
\hline Preceding calendar year state inspections (count) & & & 0.0728 & 0.003 & 0.0701 & 0.025 \\
\hline Preceding calendar year federal inspections (count) & & & -2.4426 & 0.001 & -2.5067 & 0.000 \\
\hline Preceding calendar year enforcement actions (count) & & & -0.0660 & 0.024 & -0.0823 & 0.011 \\
\hline Annual state inspections of others/\# of other facilities & & & & & 0.0246 & 0.582 \\
\hline Annual federal inspections of others/\# of other facilities & & & & & -2.9774 & 0.050 \\
\hline Annual enforcement actions at others/\# of other facilities & & & & & 0.3402 & 0.027 \\
\hline \multicolumn{7}{|l|}{ Year $2000[N=215]$} \\
\hline Regulator-regulated entity relationship index & 0.2273 & 0.000 & 0.2258 & 0.000 & 0.2239 & 0.000 \\
\hline Organic chemical manufacturing (vs. “other”) & -0.0135 & 0.843 & -0.0060 & 0.930 & -0.0460 & 0.510 \\
\hline Inorganic chemical manufacturing (vs. "other") & -0.6488 & 0.000 & -0.6394 & 0.000 & -0.6704 & 0.000 \\
\hline Major facility classification (vs. minor) & 0.4430 & 0.000 & 0.5092 & 0.000 & 0.5352 & 0.000 \\
\hline Facility employees (count) & -0.0002 & 0.021 & -0.0002 & 0.010 & -0.0003 & 0.002 \\
\hline Age of facility (years) & 0.0054 & 0.000 & 0.0047 & 0.000 & 0.0050 & 0.000 \\
\hline Facility's experience with NPDES system (years) & -0.0297 & 0.000 & -0.0298 & 0.000 & -0.0297 & 0.000 \\
\hline Facility owned by publicly-held firm (vs. privately-held) & -0.5178 & 0.000 & -0.4787 & 0.000 & -0.4791 & 0.000 \\
\hline Preceding calendar year state inspections (count) & & & -0.0128 & 0.573 & -0.0311 & 0.239 \\
\hline Preceding calendar year federal inspections (count) & & & -1.4908 & 0.000 & -1.4408 & 0.000 \\
\hline Preceding calendar year enforcement actions (count) & & & -0.0001 & 0.999 & -0.0162 & 0.759 \\
\hline Annual state inspections of others/\# of other facilities & & & & & 0.0579 & 0.147 \\
\hline Annual federal inspections of others/\# of other facilities & & & & & -1.5714 & 0.018 \\
\hline Annual enforcement actions at others/\# of other facilities & & & & & 0.2605 & 0.104 \\
\hline \multicolumn{7}{|l|}{ Year $2001[N=215]$} \\
\hline Regulator-regulated entity relationship index & 0.2087 & 0.000 & 0.2108 & 0.000 & 0.1653 & 0.000 \\
\hline Organic chemical manufacturing (vs. "other") & -0.0034 & 0.960 & -0.0320 & 0.637 & -0.0727 & 0.294 \\
\hline Inorganic chemical manufacturing (vs. "other") & -0.6274 & 0.000 & -0.6033 & 0.000 & -0.7065 & 0.000 \\
\hline Major facility classification (vs. Minor) & 0.4651 & 0.000 & 0.4159 & 0.000 & 0.8474 & 0.000 \\
\hline Facility employees (count) & -0.0001 & 0.074 & -0.0002 & 0.004 & -0.0003 & 0.000 \\
\hline Age of facility (years) & 0.0046 & 0.000 & 0.0043 & 0.000 & 0.0022 & 0.061 \\
\hline Facility's experience with NPDES system (years) & -0.0250 & 0.000 & -0.0264 & 0.000 & -0.0194 & 0.000 \\
\hline Facility owned by publicly-held firm (vs. privately-held) & -0.3525 & 0.000 & -0.2272 & 0.001 & -0.2210 & 0.001 \\
\hline Preceding calendar year state inspections (count) & & & -0.0018 & 0.925 & -0.0632 & 0.005 \\
\hline Preceding calendar year federal inspections (count) & & & -2.4120 & 0.000 & -2.5118 & 0.000 \\
\hline Preceding calendar year enforcement actions (count) & & & 0.1786 & 0.000 & 0.2091 & 0.000 \\
\hline Annual state inspections of others/\# of other facilities & & & & & 0.0700 & 0.052 \\
\hline Annual federal inspections of others/\# of other facilities & & & & & -7.2301 & 0.000 \\
\hline Annual enforcement actions at others/\# of other facilities & & & & & -1.4047 & 0.000 \\
\hline LR test of zero slopes $\left(\chi^{2}\right)$ & 796.6 & 0.000 & 1006.6 & 0.000 & 1131.6 & 0.000 \\
\hline Pseudo $R^{2}$ & & & & & & \\
\hline Goodness of fit $\left(\chi^{2}\right)$ & 6422 & 0.000 & 6212 & 0.000 & 6087 & 0.000 \\
\hline \multicolumn{7}{|l|}{ (b) Joint negative binomial estimation } \\
\hline Year $1999[N=215]$ & & & & & & \\
\hline Regulator-regulated entity relationship index & 0.1640 & 0.096 & 0.1457 & 0.142 & 0.1723 & 0.088 \\
\hline Organic chemical manufacturing (vs. "other") & -0.0737 & 0.778 & -0.1012 & 0.701 & -0.2342 & 0.421 \\
\hline Inorganic chemical manufacturing (vs. "other") & -0.9367 & 0.001 & -0.9965 & 0.000 & -1.0635 & 0.000 \\
\hline Major facility classification (vs. minor) & 0.2206 & 0.294 & 0.1232 & 0.619 & 0.2652 & 0.436 \\
\hline Facility employees (count) & -0.0004 & 0.142 & -0.0003 & 0.161 & -0.0004 & 0.119 \\
\hline Age of facility (years) & 0.0069 & 0.112 & 0.0063 & 0.145 & 0.0063 & 0.152 \\
\hline Facility's experience with NPDES system (years) & -0.0195 & 0.152 & -0.0214 & 0.115 & -0.0214 & 0.122 \\
\hline Facility owned by publicly-held firm (vs. privately-held) & -0.4483 & 0.052 & -0.5057 & 0.028 & -0.4931 & 0.033 \\
\hline Preceding calendar year state inspections (count) & & & 0.1368 & 0.129 & 0.1684 & 0.134 \\
\hline Preceding calendar year federal inspections (count) & & & -2.2660 & 0.020 & -2.3603 & 0.018 \\
\hline Preceding calendar year enforcement actions (count) & & & -0.1110 & 0.227 & -0.1446 & 0.157 \\
\hline Annual state inspections of others/\# of other facilities & & & & & -0.0347 & 0.796 \\
\hline Annual federal inspections of others/\# of other facilities & & & & & -5.2178 & 0.283 \\
\hline Annual enforcement actions at others/\# of other facilities & & & & & 0.6055 & 0.233 \\
\hline Year $2000[N=215]$ & & & & & & \\
\hline Regulator-regulated entity relationship index & 0.9927 & 0.020 & 0.2250 & 0.021 & 0.2363 & 0.016 \\
\hline Organic chemical manufacturing (vs. “other”) & 0.2233 & 0.922 & 0.0398 & 0.873 & -0.0235 & 0.932 \\
\hline Inorganic chemical manufacturing (vs. "other") & -0.7234 & 0.009 & -0.6776 & 0.015 & -0.7148 & 0.014 \\
\hline Major facility classification (vs. minor) & 0.1968 & 0.331 & 0.2466 & 0.271 & 0.2242 & 0.466 \\
\hline Facility employees (count) & -0.0002 & 0.344 & -0.0002 & 0.331 & -0.0003 & 0.261 \\
\hline
\end{tabular}


Table 3 (Continued)

\begin{tabular}{|c|c|c|c|c|c|c|}
\hline \multirow[t]{2}{*}{ Variable $^{a}$} & \multicolumn{2}{|l|}{ Model B1 } & \multicolumn{2}{|l|}{ Model B2 } & \multicolumn{2}{|l|}{ Model B3 } \\
\hline & Coeff & $p$-Value & Coeff & $p$-Value & Coeff & $p$-Value \\
\hline Age of facility (years) & 0.0078 & 0.066 & 0.0067 & 0.116 & 0.0072 & 0.097 \\
\hline Facility's experience with NPDES system (years) & -0.0299 & 0.024 & -0.0318 & 0.016 & -0.0326 & 0.015 \\
\hline Facility owned by publicly-held firm (vs. privately-held) & -0.5118 & 0.022 & -0.4633 & 0.044 & -0.4455 & 0.052 \\
\hline Preceding calendar year state inspections (count) & & & 0.0180 & 0.822 & -0.0178 & 0.871 \\
\hline Preceding calendar year federal inspections (count) & & & -1.3722 & 0.020 & -1.3281 & 0.025 \\
\hline Preceding calendar year enforcement actions (count) & & & -0.0056 & 0.983 & -0.0735 & 0.788 \\
\hline Annual state inspections of others/\# of other facilities & & & & & 0.0617 & 0.651 \\
\hline Annual federal inspections of others/\# of other facilities & & & & & -1.0191 & 0.625 \\
\hline Annual enforcement actions at others/\# of other facilities & & & & & 0.4065 & 0.503 \\
\hline \multicolumn{7}{|l|}{ Year $2001[N=215]$} \\
\hline Regulator-regulated entity relationship index & 0.2192 & 0.018 & 0.2387 & 0.010 & 0.2031 & 0.033 \\
\hline Organic chemical manufacturing (vs. “other”) & 0.0885 & 0.722 & -0.0316 & 0.898 & -0.1727 & 0.505 \\
\hline Inorganic chemical manufacturing (vs. "other") & -0.6451 & 0.018 & -0.6283 & 0.025 & -0.7435 & 0.009 \\
\hline Major facility classification (vs. minor) & 0.2988 & 0.144 & 0.1456 & 0.497 & 0.5204 & 0.079 \\
\hline Facility employees (count) & -0.0001 & 0.541 & -0.0003 & 0.188 & -0.0004 & 0.075 \\
\hline Age of facility (years) & 0.0061 & 0.145 & 0.0062 & 0.126 & 0.0034 & 0.416 \\
\hline Facility's experience with NPDES system (years) & -0.0242 & 0.074 & -0.0265 & 0.045 & -0.0164 & 0.236 \\
\hline Facility owned by publicly-held firm (vs. privately-held) & \multirow[t]{7}{*}{-0.3723} & \multirow[t]{7}{*}{0.116} & -0.2804 & 0.240 & -0.2707 & 0.258 \\
\hline Preceding calendar year state inspections (count) & & & \multirow{6}{*}{$\begin{array}{r}0.0540 \\
-0.6034 \\
0.1779\end{array}$} & \multirow{6}{*}{$\begin{array}{l}0.353 \\
0.200 \\
0.028\end{array}$} & -0.0137 & 0.864 \\
\hline Preceding calendar year federal inspections (count) & & & & & -0.6285 & 0.194 \\
\hline Preceding calendar year enforcement actions (count) & & & & & 0.2442 & 0.009 \\
\hline Annual state inspections of others/\# of other facilities & & & & & 0.0884 & 0.509 \\
\hline Annual federal inspections of others/\# of other facilities & & & & & -5.4846 & 0.019 \\
\hline Annual enforcement actions at others/\# of other facilities & & & & & -1.8744 & 0.091 \\
\hline \multirow{3}{*}{$\begin{array}{l}\text { LR test of zero slopes }\left(\chi^{2}\right) \\
\text { Pseudo } R^{2} \\
\text { Overdispersion test }\left(\chi^{2}\right)\end{array}$} & 79.53 & 0.000 & 104.89 & 0.000 & 115.16 & 0.000 \\
\hline & \multicolumn{2}{|c|}{0.0240} & \multicolumn{2}{|c|}{0.0316} & \multicolumn{2}{|c|}{0.0347} \\
\hline & 4729 & 0.000 & 4544 & 0.000 & 4429 & 0.000 \\
\hline
\end{tabular}

a Each model also includes a set of three year-specific intercept terms.

the between group and year-specific negative binomial estimates reveals fewer differences. For years 1999 and 2000, no differences appear. However, the 2001 estimates reveal differences similar to the Poisson year-specific estimates: the greater threat of federal inspections and enforcement lowers audit frequency, yet the greater use of enforcement increases audit frequency. In sum, variation across time indicates that the role of government interventions depends on changing conditions.

Finally, the zero inflated estimates reveal highly similar patterns especially in the case of between group estimates. As two notable exceptions, the statistical significance of the general threat of state inspections slips to $p=0.12$ in the Poison estimates and the significance of the differential use of federal inspections slips to $p=0.11$ in the negative binomial estimates.

\subsection{Further assessment of the robustness of conclusions}

Our construction of the cooperation-coercion index is clearly simple. As our last form of robustness, we explore alternative means of incorporating the multiple dimensions of the regulator-regulated facility relationship. We begin this exploration by implementing exploratory factor analysis on the seven individual dimensions. This analysis identifies three factors with positive eigenvalues as shown in Table 4a. The pattern of factor loadings for these three identified factors is shown in Table 4b. These loadings reveal that five of the seven dimensions load most strongly on Factor-1, while one dimension (primary regulator: state vs. federal) loads most strongly on Factor-2 and another dimension (willingness to allow unannounced access) loads most strongly on Factor-3.

Given these results, we fashion two assessment paths. First, we generate fitted values for Factor-1, Factor-2, and Factor-3 and use these fitted factors in lieu of the cooperation-coercion index in our estimation routines. Second, we construct an alternative index from the five dimensions that load most strongly on Factor-1 and use this alternative index in lieu of the initial index in our estimation routines. We also include the two remaining dimensions as two separate regressors.

We focus our assessment of robustness on the primary regressor. Estimates generated by the first assessment path fully support the conclusions reported above. The coefficient on Factor-1 $(\beta 1)$ proves significantly positive. (In the Poisson estimates, $p=0.000$ and $\beta 1 \in[0.280,0.300]$; in the negative binomial

Table 4

Factor analysis.

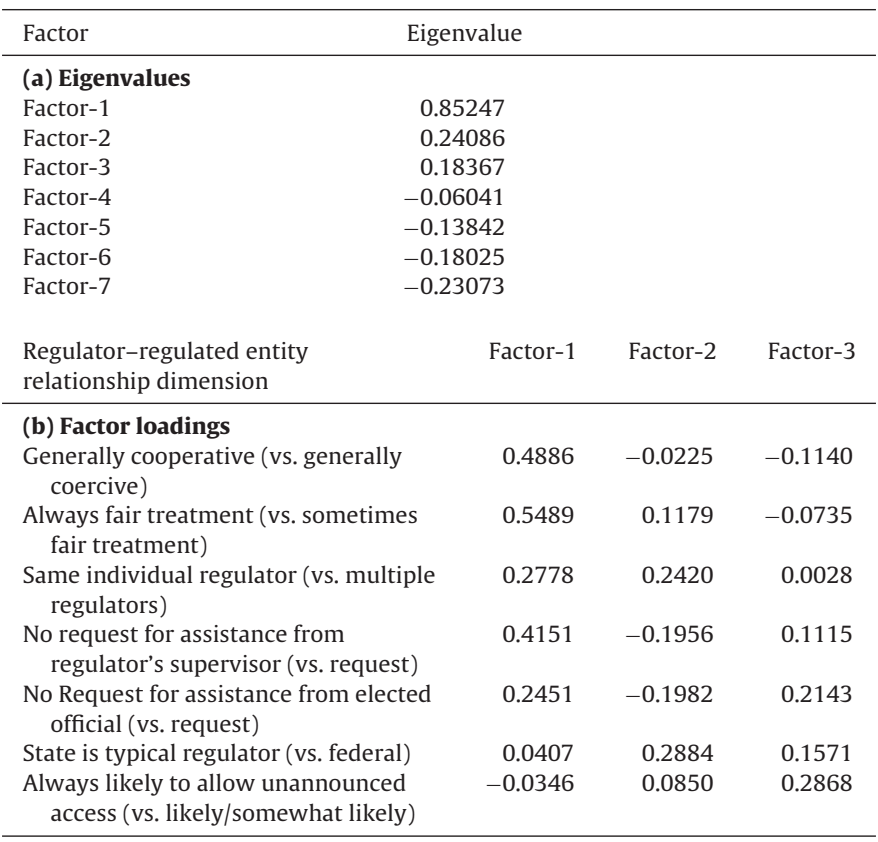


estimates, $p \in[0.055,0.067]$ and $\beta 1 \in[0.264,0.272]$.) The coefficient on Factor-2 does not prove statistically significant $(p>0.10)$. The coefficient on Factor-3 $(\beta 3)$ proves significantly positive in the Poisson estimates $(p=0.008 ; \beta 3 \in[0.202,0.205])$ but insignificantly positive in the negative binomial estimates $(p>0.10)$. Thus, we conclude that, in general, greater cooperation leads to more frequent audits, yet the type of primary regulator - state vs. federal - does not matter, while the evidence of greater trust (greater willingness to allow unannounced access) leading to more frequent audits is not supported in our better estimates.

Estimates generated by the second assessment path also support our original conclusions. The coefficient on the more narrow index of cooperation-coercion $(\beta>0)$ proves significantly positive. (In the Poisson estimates, $p=0.000$ and $\beta \in[0.232,0.242]$; in the negative binomial estimates, $p \in[0.023,0.028]$ and $\beta \in[0.216,0.218]$.) Yet the coefficients for type of primary regulator - state vs. federal - and trust (willingness to allow unannounced access) prove statistically insignificant $(p>0.357)$. Again, greater cooperation, in general, leads to more frequent audits.

\section{Policy and research implications}

The conclusions generated by the empirical results possess policy and research implications. First, these conclusions imply that environmental regulators seeking to induce better environmental management practices should employ a more cooperative approach, not a more coercive approach. Second, these conclusions imply that future research on an environmental regulator's enforcement strategy should not view this strategy as unidimensional. Instead, future research should view the enforcement strategy as representing a relationship between a regulator and a regulated entity and attempt to measure multiple dimensions of this relationship.

\section{Acknowledgements}

The research described in this article was conducted as part of a larger project financed by the U.S. Environmental Protection Agency (EPA) pursuant to STAR Research Assistance Agreement No. R-82882801-0. This article has not been formally reviewed by EPA. The views expressed in this article are solely those of Robert Glicksman and Dietrich Earnhart. EPA does not endorse any products or commercial services mentioned in this manuscript. The authors thank Donald Haider-Markel and Tatsui Ebihara for their participation in the EPA STAR grant research project. The authors also thank Chris Drahozal, Joel Mintz, and Cliff Rechtschaffen for their very helpful insight. Robert Glicksman thanks Erica Dew for her valuable research assistance. Dietrich Earnhart thanks Dylan Rassier, J. Mark Leonard, and Trisha Shrum for their valuable research assistance.

\section{Appendix A. Supplementary data}

Supplementary data associated with this article can be found, in the online version, at http://dx.doi.org/10.1016/j.irle.2015.02.003.

\section{References}

American Society for Testing and Materials (ASTM), 2003. Standard Practice for Environmental Regulatory Compliance Audits., pp. 1-4.

Andreen, W., 2007. Motivating enforcement: institutional culture and the Clean Water Act. Pace Environ. Law Rev. 24, 67-98.

Anton, W.R., Deltas, G., Khanna, M., 2004. Incentives for environmental selfregulation and implications for environmental performance. J. Environ. Econ. Manag. 48, 632-654.
Arimura, T., Hibiki, A., Katayama, H., 2008. Is a voluntary approach an effective environmental policy instrument? A case for environmental management systems. J. Environ. Econ. Manag. 55 (3), 281-295.

Arimura, T., Darnall, N., Katayama, H., 2011. Is ISO 14001 a gateway to more advanced voluntary action? The case of green supply chain management. J. Environ. Econ. Manag. 61, 170-182.

Ayers, I., Braithwaite, J., 1992. Responsive Regulation: Transcending the Deregulation Debate. Oxford University Press, New York.

Barla, P., 2007. ISO 14001 certification and environmental performance in Quebec's pulp and paper industry. J. Environ. Econ. Manag. 55, 291-306.

Becker, G., 1968. Crime and punishment: an economic approach. J. Polit. Econ. 76, 169-217.

Burby, R., Paterson, R., 1993. Improving compliance with state environmental regulations. J. Policy Anal. Manag. 12, 753-756.

Burby, R., 1995. Coercive v. cooperative pollution control: comparative study of state programs to reduce erosion and sedimentation pollution in urban areas. Environ. Manag. 19, 359-361.

Cameron, A.C., Trivedi, P.K., 1998. Regression Analysis of Count Data. Cambridge University Press, Cambridge, UK.

Cohen, M., 2000. Empirical research on the deterrent effect of environmental monitoring and enforcement. Environ. Law Report. 30, 10245-10252.

Crow, M., 2000. Beyond experiments. Environ. Forum 37 (3), 18-29.

Earnhart, D., Harrington, D.R., 2014. Effect of audits on the extent of compliance with wastewater discharge limits. J. Environ. Econ. Manag. 68 (2), 243-261.

Ebihara, T., Irminger, D., 2005. Correlation of Environmental Management Practices to Environmental Performance for the U.S. Chemical Manufacturing Industry. Working Paper. University of Kansas, School of Engineering.

EPA, 1997. EPA Strategic Plan, EPA/190-R-97-002.

EPA, 1999, May. EPA/CMA Root Cause Analysis Pilot Project, Document No. EPA-305R-99-001.

EPA, 2000. U.S. EPA Strategic Plan 2000. Environmental Protection Agency, Washington, DC.

Evans, M., Liu, L., Stafford, S., 2011. Do environmental audits improve long-term compliance? Evidence from manufacturing facilities in Michigan. J. Regul. Econ. 40, 279-302.

Faure, M., 2012. Effectiveness of environmental law: what does the evidence tell us? William Mary Environ. Law Policy Rev. 36, 293-300.

Glicksman, R., Earnhart, D., 2007. The comparative effectiveness of government interventions on environmental performance in the chemical industry. Stanford Environ. Law J. 26, 112-139.

Harrison, K., 1995. Is cooperation the answer? Canadian environmental enforcement in comparative context. J. Policy Anal. Manage. 14, 221-223.

Hawkins, K., 1984. Environment and Enforcement: Regulation and the Social Definition of Pollution. Oxford University Press, New York.

Helland, E., 1998. The enforcement of pollution control laws: inspections, violations, and self-reporting. Rev. Econ. Stat. 80 (1), 141-153.

Kagan, R., Gunningham, N., Thornton, D., 2003. Explaining corporate environmental performance: how does regulation matter? Law Soc. Rev. 37, 51-90.

Karpoff, J., Lott Jr., J.R., Wehrly, E.W., 2005. The reputational penalties for environmental violations: empirical evidence. J. Law Econ. 48, 653-675.

Khanna, M., Widyawati, D., 2011. Fostering regulatory compliance: the role of environmental self-auditing and audit policies. Rev. Law Econ. 7, 129-163.

Magat, W.A., Viscusi, W.K., 1990. Effectiveness of the EPA's Regulatory Enforcement: the case of industrial effluent standards. J. Law Econ. 33, 331-360.

Malloy, T., 2003. Regulation, compliance and the firm. Temple Law Rev. 76, 451-454.

Markel, D., 2000. The role of deterrence-based enforcement in a 'Reinvented' state/federal relationship: the divide between theory and reality. Harv. Environ. Law Rev. 24, 1-5.

Markel, D., 2005. 'Slack' in the administrative state and its implications for governance: the issue of accountability. Oregon Law Rev. 84, 1-22.

Mintz, J., 1995. Enforcement at the EPA: High Stakes and Hard Choices. University of Texas Press, Austin.

Nakamura, M., Takahashi, T., Vertinsky, I., 2001. Why Japanese firms choose to certify: a study of managerial responses to environmental issues. J. Environ. Econ. Manag. 42, 23-52.

Paxson, M.C., 1992. Response Rates for 183 Studies. Working Paper. Washington State University.

Rechtschaffen, C., 1998. Deterrence vs. cooperation and the evolving theory of environmental enforcement. South. Calif. Law Rev. 71, 1181-1188.

Rechtschaffen, C., 2004. Promoting pragmatic risk regulation: is enforcement discretion the answer? Univ. Kansas Law Rev. 52, 1327-1361.

Rechtschaffen, C., Markell, D., 2003. Reinventing Environmental Enforcement and the State/Federal Relationship. Environmental Law Institute, Washington, DC.

Scholz, J., 1984. Cooperation, deterrence, and the ecology of regulatory enforcement. Law Soc. Rev. 18, 179-180.

Short, J., Toffel, M., 2010. Making self-regulation more than merely symbolic: the critical role of the legal environment. Adm. Sci. Q. 55, 361-396.

Spence, D., 2001. Can the second generation learn from the first? Understanding the politics of regulatory reform. Cap. Univ. Law Rev. 29, 205-207.

Stoughton, M., Herb, J., Sullivan, J., Crow, M., 2001. Toward integrated approaches to compliance assurance. Environ. Law Rep. 31, 11266-11283.

Stretesky, P., Gabriel, J., 2005. Self-policing and the environment: predicting selfdisclosure of Clean Air Act violations under the U.S. Environmental Protection Agency's audit policy. Soc. Nat. Resour. 18 (10), 871-887. 
Toffel, M., Short, J., 2011. Coming clean and cleaning up: does voluntary selfreporting indicate effective self-policing. J. Law Econ. 54, 609-649.

Vandenbergh, M., 2003. Beyond elegance: a testable typology of social norms in corporate environmental compliance. Stanf. Environ. Law J. 22, 63-64.
Wilson, C.L., Thomas, W.L., 1998. Environmental audits and corporate strategies Corp. Environ. Strategy 5, 4-17.

Zinn, M., 2002. Policing environmental regulatory enforcement: cooperation, capture and citizen suits. Stanf. Environ. Law J. 21, 81-90. 